\title{
Estruturas e Histórias Deformacionais Contrastantes dos Granitos Sintectônicos de Campina Grande e Serra Redonda, Província Borborema, NE do Brasil
}

\section{Contrasting Structures and Deformational History of Syntectonic Granites of Campina Grande and Serra Redonda, Borborema Province, NE Brazil}

\author{
Sérgio Wilians de Oliveira Rodrigues' (sergio.rodrigues@cprm.gov.br)e \\ Carlos José Archanjo² (archan@usp.br) \\ 'CPRM - Serviço Geológico do Brasil, Superintendência Regional de São Paulo \\ R. Costa 55, CEP 01304-010, São Paulo, SP, BR \\ ${ }^{2}$ Departamento de Mineralogia e Geotectônica - Instituto de Geociências - USP, São Paulo, SP, BR
}

Recebido em 03 de maio de 2010; aceito em 08 de outubro de 2010

\section{RESUMO}

Os Granitos Campina Grande e Serra Redonda são intrusivos no contato do embasamento paleoproterozoico (Domínio Alto Moxotó) com orto- e paragnaisses tonianos (Domínio Alto Pajeú) da Província Borborema (NE do Brasil). O Granito Campina Grande (idade U-Pb $=581 \pm 2 \mathrm{Ma}$ ) destaca-se por sua estrutura concêntrica e forma ovalada, enquanto o Granito Serra Redonda (idade U-Pb $=576 \pm 3 \mathrm{Ma}$ ) exibe uma estrutura tabular alongada na direção NE-SW. Estes plútons são separados pela zona de cisalhamento transcorrente Galante, que apresenta cinemática sinistral. O estudo da anisotropia de suscetibilidade magnética (ASM) realizado em 64 afloramentos destes granitos possibilitou o mapeamento das estruturas internas destes plútons e explorar as relações entre magmatismo e deformação em relação ao ambiente orogênico. As tramas magnéticas são concordantes com a estrutura das rochas metamórficas encaixantes. O controle do alojamento do Granito Serra Redonda por zonas de cisalhamento transcorrentes é indicado pela presença de foliações sigmoidais que definem bandas de cisalhamento associadas a Zona de Cisalhamento Galante. Em contraste, a petrotrama magnética/magmática associadas ao Granito Campina Grande parece ser moldada pela ação das forças do corpo (ascensão/alojamento). O plúton exibe uma trama planar (semi)concêntrica que mergulha para o interior da intrusão e lineações em alto ângulo com o alinhamento da foliação. Sua origem é atribuída à migração do magma granítico sobre uma rampa que mergulha para sudoeste, com a lineação magnética praticamente perpendicular à direção de fluxo. As estruturas contrastantes nas duas intrusões refletem os regimes deformacionais distintos a que foram submetidos os magmas durante sua cristalização. Elas ressaltam ainda a natureza episódica da deformação orogênica e o seu impacto no desenvolvimento da trama de plútons sin-tectônicos.

Palavras-chave: ASM; Granitos; Colocação; Zona de cisalhamento; Província Borborema.

\begin{abstract}
The Campina Grande and Serra Redonda Granites are intrusive along the contact of the Paleoproterozoic basement (Alto Moxotó Domain) with the Tonian gneisses (Alto Pajeú Domain) of the Borborema Province (northeast Brazil). The Campina Grande Granite $(\mathrm{U}-\mathrm{Pb}$ age $=581 \pm 2 \mathrm{Ma})$ shows a concentric oval-shaped structure whereas the Serra Redonda Granite $(\mathrm{U}-\mathrm{Pb}$ age $=576 \pm 3 \mathrm{Ma})$ has a tabular shape, elongated in the NE-SW direction. The plutons are separated by the left-lateral Galante transcurrent shear zone. In this study, the anisotropy of magnetic susceptibility (AMS) was applied to 64 outcrops of granites to determine the internal structures of these plutons and to explore the relationship between magmatism and deformation in an orogenic setting. The magnetic fabrics are concordant with the metamorphic structure of the host rocks. Strike-slip shear zones controlled the emplacement of the Serra Redonda Granite, as indicated by sigmoidal foliation, defining shear bands associated with the Galante shear zone. In contrast, the magmatic/magnetic fabric of the Campina Grande granite seems to have been produced by body (ascensional) forces. The pluton displays an inward dipping,
\end{abstract}


concentric planar fabric parallel to the wall rock contact and lineations highly oblique to the foliation trend. The fabric of the Campina Grande pluton is consistent with a magma moving over a ramp dipping to southwest, with the lineation at high angle to the NE-trending flow direction. The contrasting structures of the plutons reflect the episodic nature of orogenic deformation, which was punctuated by the alternation of weak and strong strains, affecting the fabric development of the syntectonic intrusions.

Keywords: AMS; Granites; Emplacement; Shear zone; Province Borborema.

\section{INTRODUÇÃO}

A associação entre magmas graníticos e sítios extensionais em ambiente sin- e pós-colisional tem sido verificada em diversos cinturões orogênicos de diferentes idades. Numerosos estudos estruturais em plútons graníticos confirmam a forte conexão entre a trama (fabric) magmática e a deformação regional, especialmente em zonas de cisalhamento (e.g., Hutton, 1988; Vigneresse, 1995; Brown e Solar, 1998; Cruden, 2006 etc.). O estudo da relação entre o magmatismo e a deformação constitui uma das ferramentas essenciais para entender os mecanismos de transferência de massa e diferenciação da crosta e, assim, a própria evolução estrutural de um orógeno. Esse tipo de estudo tomou um grande impulso com a utilização da anisotropia de suscetibilidade magnética (ASM), que é utilizada para caracterizar a estrutura interna de corpos ígneos e seus mecanismos de alojamento (Bouchez, 2002).

Um amplo e diversificado magmatismo granítico associado a um complexo sistema de zonas de cisalhamento caracterizam a orogênese brasiliana na Província Borborema (Santos e Medeiros, 1999; Brito Neves et al., 2003; Ferreira et al., 2004). A província (Figura 1) é formada por bacias vulcano-sedimentares neoproterozoicas margeadas por um embasamento paleoproterozoico contendo, localmente, núcleos arqueanos (Almeida et al., 1981; Brito Neves, Santos, Van Schmus, 2000). As zonas de cisalhamento recortam e subdividem a província em diferentes domínios crustais e muitas delas controlam estruturalmente a colocação de plútons graníticos (Archanjo, Bouchez, Corsini, 1994; Vauchez e Neves, 1997; Sá et al., 1999; Archanjo, Silva, Caby, 1999; Archanjo et al., 2002; Weinberg, Sial, Mariano, 2004; Neves et al., 2006; Archanjo et al., 2008).

Neste trabalho apresentamos a ASM do Complexo Granítico Campina Grande (Almeida, Guimarães, Silva Filho, 2002a), que se situa na junção de domínios crustais de idade e composição diferenciada. O complexo é formado por dois corpos, o Granito Campina Grande (GCG) e o Serra Redonda (GSR), separados por uma zona de cisalhamento transcorrente. Ressalta-se que estes corpos podem ser interpretados como pulsos ou domínios estruturais distintos representativos de uma única intrusão. A ASM forneceu a trama destes plútons graníticos e permitiu estabelecer relações entre o magmatismo e as zonas de cisalhamento adjacentes. Os dados iniciais da ASM nos Granitos Campina Grande e Serra Redonda estão apresentados em Archanjo et al. (2008) e Rodrigues, Archanjo e Launeau (2009). Esses trabalhos descrevem as tramas magnéticas e a orientação preferencial de forma (OPF) de silicatos do GCG, bem como apresentam uma idade U-Pb (SHRIMP) em zircão de $576 \pm 3$ Ma para o GSR. A intrusão do Serra Redonda sucede o GCG, que forneceu uma idade U-Pb (TIMs) em zircão de $581 \pm 2$ (Almeida, Guimarães, Silva Filho, 2002a).

\section{CONTEXTO GEOLÓGICO REGIONAL}

Conforme Rodrigues e Brito Neves (2008), a área de estudo engloba principalmente dois compartimentos tectônicos do arcabouço da Província Borborema (Figura 2), a saber, de norte para sul: Terreno Alto Pajeú (TAP), composto de ortognaisses (Granitoides Cariris Velhos) e rochas supracrustais (Complexo São Caetano) de idade toniana (Brito Neves et al., 2001a; Kozuch, 2003; Santos et al., 2010); Terreno Alto Moxotó (TAM), estruturado por ortognaisses variados, migmatitos e rochas máficas-ultramáficas de idade paleoproterozoica (Brito Neves et al., 2001b; Santos, Nutman, Brito Neves, 2004). Ambos são partes integrantes do Domínio da Zona Transversal, que agrega uma série de compartimentos tectônicos da Província Borborema situados entre os lineamentos Patos e Pernambuco.

O Terreno Alto Moxotó (Brito Neves et al., 2001b; Santos, Ferreira, Silva Júnior, 2002) na área estudada é caracterizado principalmente por ortognaisses bandados de composição variada relacionados ao denominado Complexo Floresta (Santos, Nutman, Brito Neves, 2004; Santos et al., 2008). As determinações geocronológicas dos ortognaisses bandados apresentam idades U-Pb em zircões com valores paleoproterozoicos (idades de $2016 \pm 26 \mathrm{Ma}, 2109$ $\pm 8 \mathrm{Ma}, 2393 \pm 110 \mathrm{Ma}$; Brito Neves et al., 2001b; Santos, Nutman, Brito Neves, 2004). 

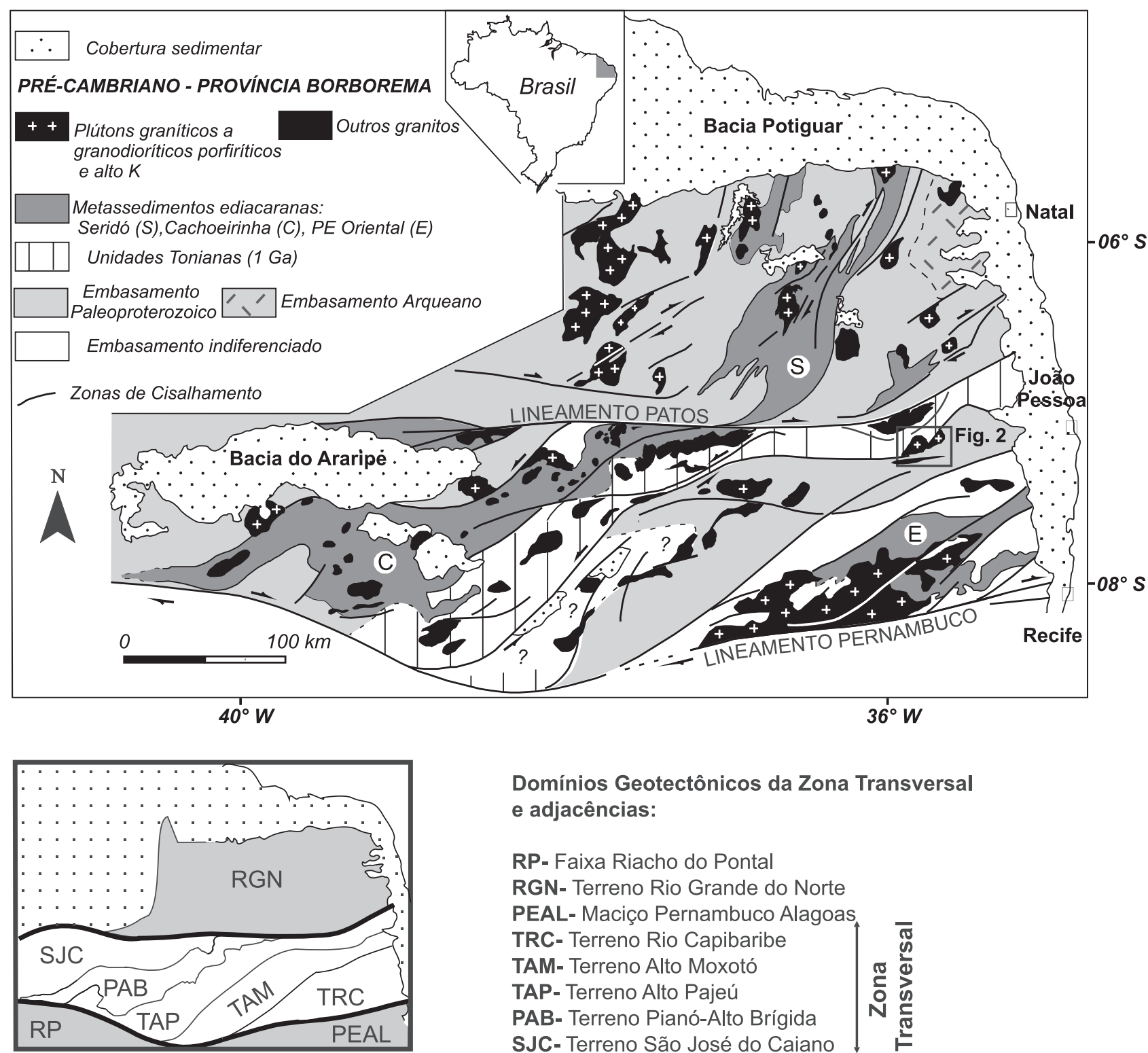

\section{Domínios Geotectônicos da Zona Transversal e adjacências:}

RP- Faixa Riacho do Pontal

RGN- Terreno Rio Grande do Norte

PEAL- Maciço Pernambuco Alagoas

TRC- Terreno Rio Capibaribe

TAM- Terreno Alto Moxotó

TAP- Terreno Alto Pajeú

PAB- Terreno Pianó-Alto Brígida

SJC- Terreno São José do Caiano

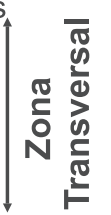

Figura 1. Contexto geológico e geotectônico regional da Província Borborema Oriental (modificado de Archanjo e Fetter, 2004), com a "Zona Transversal" situada entre os lineamentos Patos e Pernambuco. Domínios tectônicos de acordo com Brito Neves, Santos e Van Schmus (2000).

O TAM é limitado com o Terreno Alto Pajeú (TAP) por zonas de cisalhamento transcorrentes e pelo Sistema de Empurrão Riachão do Bacamarte. Principalmente na porção leste da área estudada apresenta predomínio de foliações NE-SW de médio ângulo e lineações dispersas com concentração máxima no quadrante SE (Figura 2, Domínio E), diferente do padrão estrutural observado próximo a zonas de cisalhamento de alto ângulo (Z. C. Galante, Matinhas etc.) e correlato ao padrão observado no Sistema de Empurrão Riachão do Bacamarte.
O "Terreno Alto Pajeú" é composto por sequências de rochas metassedimentares e metavulcano-sedimentares (Complexo São Caetano) e metagranitoides (Metagranitoides Cariris Velhos) de idade toniana (Brito Neves et al., 2001a; Kozuch, 2003; Santos et al., 2010).

O Complexo São Caetano é caracterizado por Santos, Ferreira e Silva Júnior (2002) como uma sequência metassedimentar e metavulcanoclástica dominantemente félsica-intermediária. Os protólitos dos paragnaisses, quartzitos, (granada)-muscovita-biotita gnaisse e micaxistos 


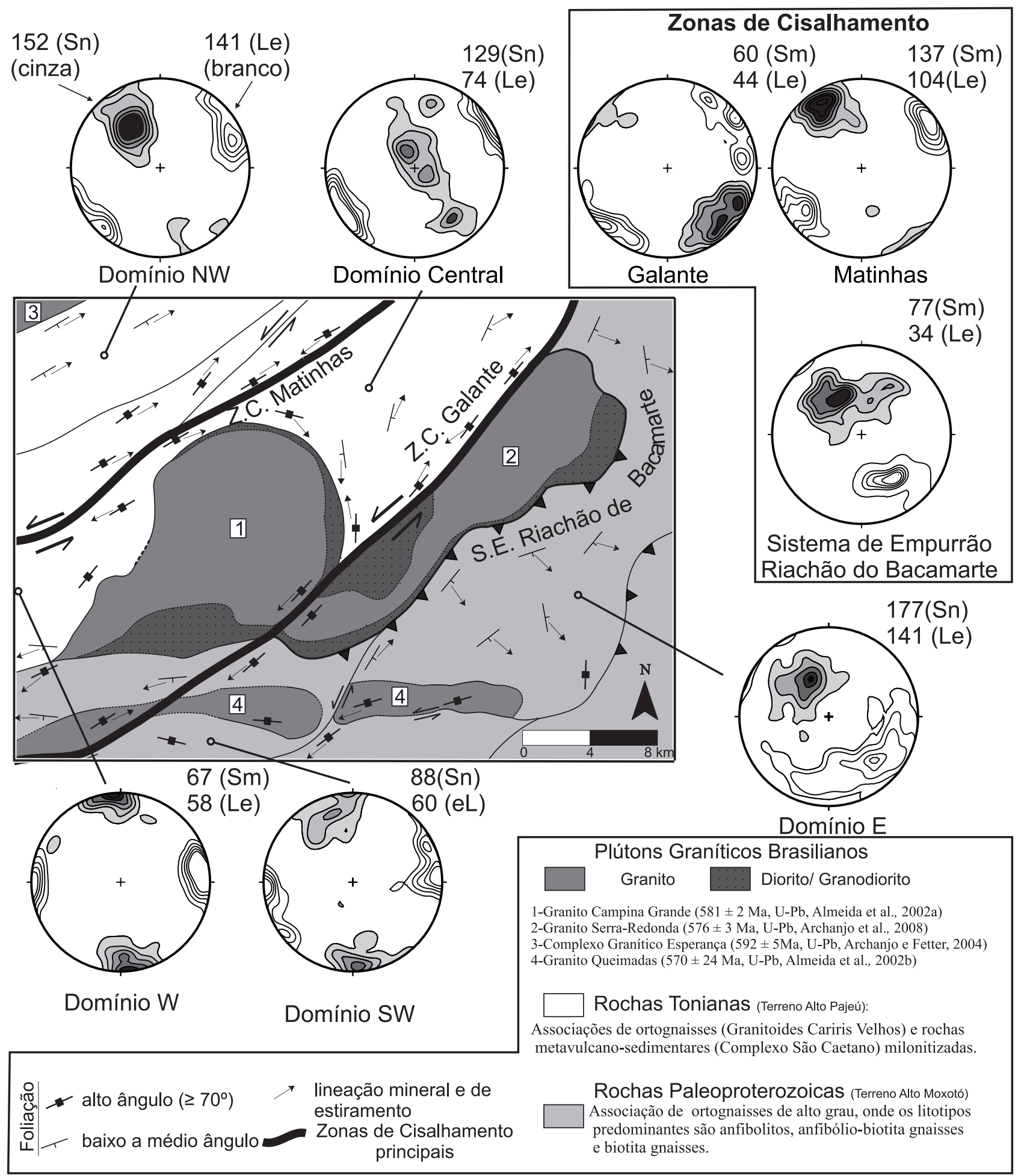

Figura 2. Domínios estruturais e arcabouço geológico da área de estudo. Estereogramas em semiesfera inferior com isofrequência de contagem $(2,4,6,8$ e 10). Contornos em branco para lineações e contornos preenchidos em cinza para foliações. 
são pelitos/psamitos, grauvacas e rochas vulcanoclásticas (Santos, 1995). Este complexo apresenta datações U-Pb com idades tonianas em zircões magmáticos de rochas metavulcânicas (995 \pm 12 Ma, Kozuch, 2003) e em zircões detríticos de rochas metavulcano-sedimentares ( 980 a 964 Ma, Kozuch, 2003).

Os ortognaisses graníticos (Metagranitoides Cariris Velhos) ocorrem como corpos subordinados nas rochas do Complexo São Caetano (paralelizados à foliação milonítica) ou como corpos mapeáveis de algumas dezenas ou centenas de metros. Apresentam datações U-Pb em zircões magmáticos que apontam idades tonianas (1000 a 920 Ma, Brito Neves et al., 2001a; Kozuch, 2003; Santos et al., 2010).

O TAP na região de estudo apresenta direção E-W/NE-SW devido ao forte controle estrutural das zonas de cisalhamento transcorrente sinistrais (Z. C. Matinhas e Z. C. Galante), conforme pode ser observado na Figura 2. Estas zonas de cisalhamento sinistrais, juntamente com outras zonas de cisalhamento destrais que ocorrem a oeste (Z. C. Campina Grande, Z. C. Catolé), delimitam um complexo sistema de estruturas provavelmente consorciadas com o Lineamento Patos. Este sistema de estruturas é denominado por Rodrigues e Archanjo (2008) como "Sistema de Cisalhamento de Campina Grande". Os referidos autores interpretam este conjunto de zonas de cisalhamento a um sistema transcorrente conjugado resultante de esforços compressivos de direção NNW-SSE, que também são responsáveis pelo cavalgamento do embasamento paleoproterozoico (Terreno Alto Moxotó) sobre o plúton granítico brasiliano Serra Redonda.

Os terrenos Alto Moxotó e Alto Pajeú na área estudada são cortados por plútons brasilianos de idade ediacarana (complexos magmáticos Esperança, Campina Grande e Queimadas), stocks graníticos e diques de composição intermediária a félsica.

O Complexo Magmático Esperança é formado por corpos de tonalito, sienogranito (plúton de Pocinhos), anfibólio-biotita granito porfirítico grosso e leucogranito (Archanjo e Fetter, 2004). O complexo possui uma forma de sigmoide, limitado a norte pelos milonitos de baixa temperatura do Lineamento Patos. O complexo magmático apresenta idades U-Pb de $592 \pm 5 \mathrm{Ma}$ (Archanjo e Fetter, 2004) no sienogranito (plúton de Pocinhos) e $581 \pm 3$ Ma no granito porfirítico grosso (Sampaio et al., 2003). Archanjo e Fetter (2004), através de estudo sistemático de anisotropia de suscetibilidade magnética (ASM), mapearam a estrutura magmática do Complexo Magmático Esperança, associando a colocação deste com injeções de sheets graníticos em diferentes regimes de deformação.

O Plúton Queimadas (Almeida, Guimarães, Silva Filho, 2002b) constitui uma intrusão tabular alongada E-W intru- dido entre rochas paleoproterozoicas (Figura 2). Caracteriza-se como uma suíte de biotita-anfibólio monzogranito. Almeida, Guimarães e Silva Filho (2002b) apresentam a idade de $570 \pm 25 \mathrm{Ma}$ (U-Pb em zircões) para este corpo.

\section{Granitos Campina Grande e Serra Redonda}

O Complexo Granítico Campina Grande abrange os granitos Campina Grande (GCG) e Serra Redonda (GSR). Eles são facilmente identificáveis em imagens de sensores remotos e fotografias áreas, constituindo importantes feições morfológicas, com características distintas. O GCG destaca-se por sua estrutura semiconcêntrica, enquanto o GSR apresenta uma estrutura tabular alongada (Figura 2). Os plútons são delimitados por zonas de cisalhamento transcorrentes e pelo empurrão de Riachão de Bacamarte. As zonas transcorrentes apresentam cinemáticas sinistral (Matinhas e Galante), enquanto o empurrão de Riachão de Bacamarte transporta as rochas paleoproterozoicas para N e NW.

Os granitos Campina Grande e Serra Redonda ocupam o contato entre as rochas paleoproterozoicas e tonianas. Rodrigues (2008) mapeou duas fácies petrográficas principais para o Complexo Granítico Campina Grande, uma porfirítica dominante e outra máfica. A fácies porfirítica caracteriza-se por fenocristais de K-feldspato (idiomórficos a subidiomórficos, de 2 a $5 \mathrm{~cm}$, no geral) imersos em uma matriz constituída essencialmente por feldspato (plagioclásio e K-feldspato), quartzo, biotita e anfibólio, mesocrático a leucocrático (20 a 25\% de minerais máficos) e inequigranular. Esta fácies contém enclaves microgranulares máficos, em geral com formas arredondadas e elípticas, às vezes alongadas e orientadas, que apresentam dimensões que variam de alguns centímetros até $1 \mathrm{~m}$. Estes enclaves são interpretados como autólitos e são considerados como evidência de coexistência e mistura de magmas. Almeida, Guimarães e Silva Filho (2002a) encontraram semelhanças químicas e isotópicas entre as rochas máficas e félsicas, sugerindo fontes similares para as duas unidades.

A fácies máfica é formada pelo predomínio de dioritos, quartzo-dioritos e lentes subordinadas de granitos e granodioritos que apresentam contatos graduais ou bruscos entre si (Figura 3E). Predominam termos equigranulares faneríticos finos a médios. Localmente, observa-se um bandamento caracterizado pela variação da granulometria e presença de fenocristais. Também ocorrem neles intercalações da fácies porfirítica com contatos brusco, irregulares ou paralelizados.

Texturas e estruturas magmáticas são comuns na porção interna de ambos os plútons. A foliação magmática é definida por megacristais de feldspatos alinhados e/ou por enclaves microgranulares máficos (Figura 3C). 

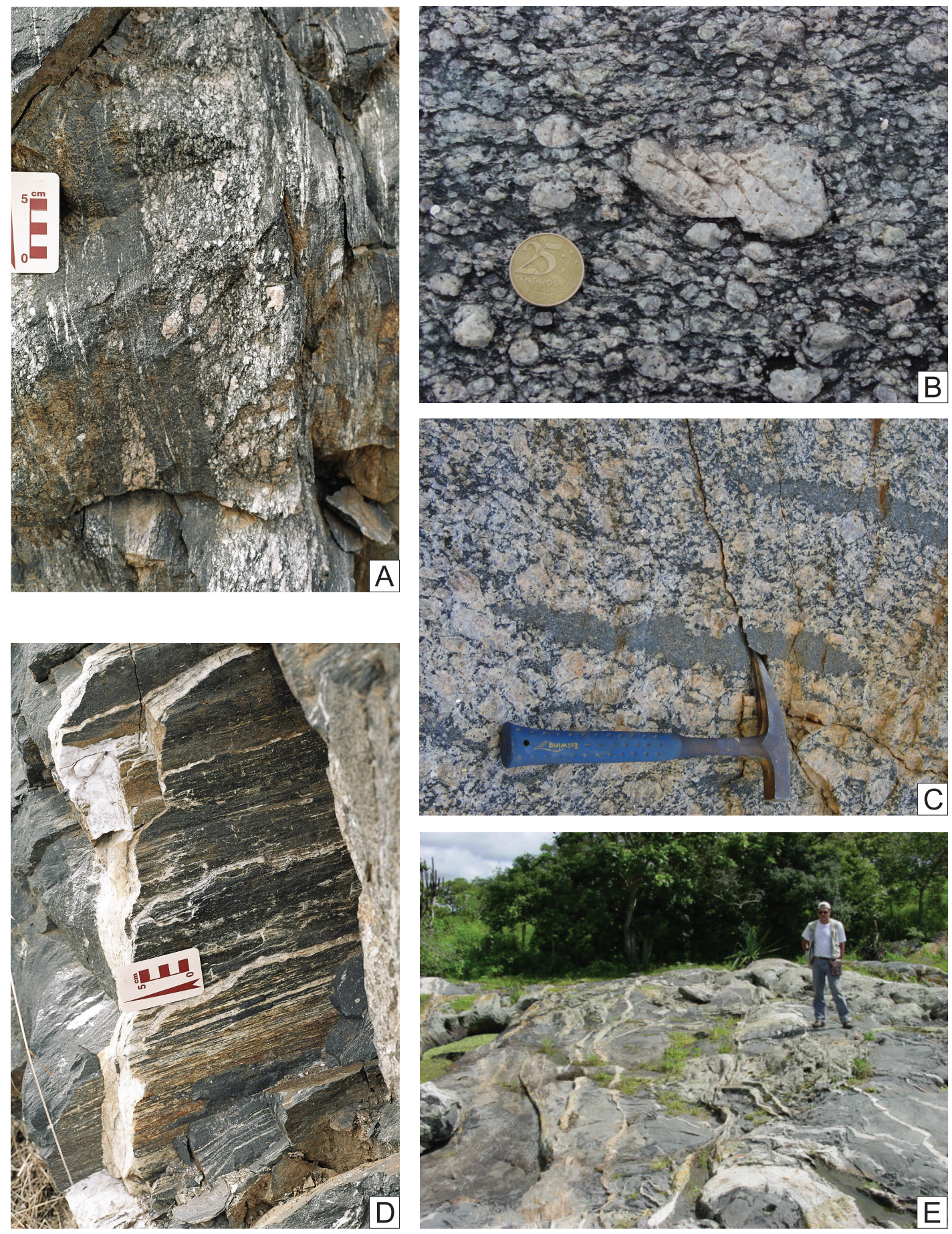

Figura 3. A. Bandas de diorito e granodioritos intercalado com granito porfirítico, ambos paralelizados com foliação milonítica associada à Zona de Cisalhamento Galante (BR-220: 8 km a leste de Campina Grande). B. Estrutura do tipo dominó em porfiroclasto de feldspato do granito Serra Redonda associado à Zona de Cisalhamento Galante (Município de Serra Redonda). C. Enclaves microgranulares máficos da fácies porfirítica fortemente alongados e estirados (BR-220: 2 km a leste de Campina Grande). D. Foliações miloníticas observadas no Complexo Granítico de Campina Grande, com marcante lineação de estiramento (BR-220, 10 km a Leste de Campina Grande). E. Fácies máfica do Complexo Granítico Campina Grande: dioritos com intercalações centimétricas de fase granítica. 
Nas bordas dos granitos Campina Grande e Serra Redonda são encontradas foliações miloníticas e protomiloníticas (Figuras 3A e 3B), geralmente paralelas à foliação magmática, porém localmente oblíquas entre si. As foliações tectônicas ocorrem sempre associadas às zonas de cisalhamento, como também desenvolvem faixas descontínuas de pouca espessura nos domínios internos dos granitos. Lineações de estiramento (Figura 3D), no geral com baixo ângulo de caimento (lineações horizontais a sub-horizontais e também oblíquas), estão comumente associadas às zonas de cisalhamentos sinistrais (Figura 2). Também são encontradas lineações com alto ângulo de caimento (down dip) na zona de empurrão de Riachão de Bacamarte. Nas zonas miloníticas as microestruturas são típicas de deformação dúctil no quartzo (recristalização dinâmica) enquanto no K-feldspato predomina o microfraturamento (Figura 3B). As relações observadas entre as texturas dos granitos sugerem um desenvolvimento da milonitização ou parte do processo da mesma, em um evento sin a tardi-magmático (Rodrigues e Archanjo, 2008; Rodrigues, Archanjo, Launeau, 2009).

\section{ANISOTROPIA DE SUSCETIBILIDADE MAGNÉTICA (ASM)}

\section{Amostragem e determinação da ASM}

Foram coletados um total de 330 cilindros de $2,5 \mathrm{~cm}$ de diâmetro e $7 \mathrm{~cm}$ de altura extraídos com uma perfuratriz portátil e orientados diretamente no campo. A amostragem forneceu um total de 64 estações (pontos) de medida, sendo 37 no GCG e 27 no GSR (Figura 4).

Os procedimentos de amostragem e de obtenção de dados de ASM são descritos por Bouchez (1997). A medida da ASM foi realizada em espécimes de rocha de 2,2 cm de altura por 2,5 cm de diâmetro em um susceptômetro Kappabridge KLY-4 (AGICO) do Laboratório de Paleomagnetismo do Instituto de Astronomia, Geofísica e Ciências

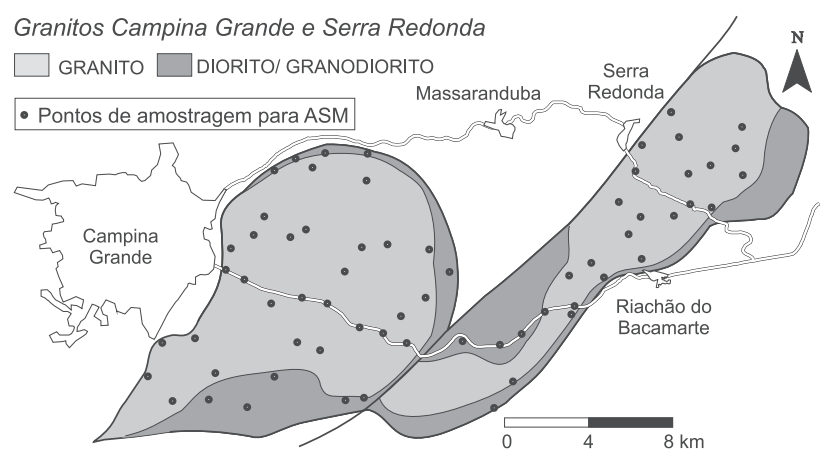

Figura 4. Localização das estações de amostragem de ASM.
Atmosféricas (IAG) da Universidade de São Paulo (USP). A ASM pode ser definida por um tensor de terceira ordem cuja representação geométrica é um elipsoide $\left(K_{1}>K_{2}>\right.$ $K_{3}$ ). O grau de anisotropia $P$ é dado pela relação $K_{l} / K_{3}$; quando $P=1$ (esfera) a suscetibilidade é considerada isotrópica e, à medida que $P$ aumenta, o grau de excentricidade do elipsoide aumenta igualmente. A forma do elipsoide varia de oblato $\left(K_{1}=K_{2}>>K_{3}\right)$, prolato $\left(K_{1}>>K_{2}=K_{3}\right)$, e triaxial ou neutro $\left(K_{1}>K_{2}>K_{3}\right)$. A simetria pode ser determinada pelo parâmetro $T$, expresso por:

$$
T=\ln F-\ln L / \ln F+\ln L,
$$

onde $F=K_{2} / K_{3}$, e $L=K_{1} / K_{2}$. T varia de 0 a 1 para elipsoides triaxiais a oblatos e de 0 a -1 para elipsoides triaxiais a prolatos. As Tabelas 1 e 2 apresentam os parâmetros calculados de ASM das estações analisadas.

\section{Anisotropia magnética e parâmetros de forma}

A suscetibilidade magnética $\left(K_{m}\right)$ varia de 0,458 a $26,448\left(10^{-3} \mathrm{SI}\right)$, com o predomínio de sítios com $K_{m}>1 \mathrm{x}$ $10^{-3} \mathrm{SI}$. As amostras com maiores valores de suscetibilidade magnética são encontrados nos granodioritos e dioritos (fácies máfica). O grau de anisotropia magnética é baixo, não ultrapassando valores maiores que 1,35.

Os sítios apresentam uma baixa dispersão direcional (parâmetro e Tabelas 1 e 2) de $K_{3}$ (foliação magnética) e uma maior dispersão para $K_{2}$ e $K_{1}$ (lineação magnética). Em alguns sítios verificou-se uma forte dispersão de $K_{2}$ e $K_{3}$ (CG-15, CG-16 e CG-17), em parte refletindo o predomínio de elipsoides oblatos (Figura 5), sendo que nestes sítios apenas a foliação magnética possui significado estrutural. O predomínio de elipsoides oblatos é verificado no Granito Campina Grande, enquanto o Serra Redonda apresenta uma população de elipsoides prolatos a oblatos.

A Figura 6 apresenta os padrões de foliações e lineações magnéticas obtidas no Complexo Granítico de Campina Grande.

\section{Orientação dos parâmetros direcionais}

A trama magnética $\left(K_{1}\right.$ e $\left.K_{3}\right)$ exibe um padrão distinto, porém bem definido em cada plúton. No Granito Campina Grande as lineações caem dominantemente para sul e sudeste enquanto a foliação define uma estrutura concêntrica com caimentos mergulhando, no geral, para o interior do corpo. $\mathrm{O}$ arranjo da trama magnética, notadamente a foliação, é semelhante ao bandamento composicional/foliação de fenocristais mapeados no interior do maciço (cf. Figura 6). Estes dados atestam a boa correspondência entre as 
Tabela 1. Dados de anisotropia de suscetibilidade magnética (ASM) dos sítios localizados no Granito Campina Grande. $\boldsymbol{K}_{m}=$ suscetibilidade magnética média; $\mathbf{P}=$ grau de anisotropia; $\mathbf{T}=$ parâmetro de forma; $\boldsymbol{K}_{1}=$ lineação magnética; $K_{3}=$ polo da foliação magnética; $\mathbf{e}_{1}$ e $\mathbf{e}_{3}=$ semiângulo do cone de dispersão $(1 \sigma)$ em torno da média tensorial.

\begin{tabular}{|c|c|c|c|c|c|c|c|c|c|}
\hline \multirow[b]{2}{*}{ Ponto } & \multicolumn{2}{|c|}{ Localização } & \multicolumn{3}{|c|}{ Dado escalar } & \multicolumn{4}{|c|}{ Dado direcional } \\
\hline & Long (W) & Lat(S) & $\begin{array}{c}K_{m} \\
(m S I)\end{array}$ & $\mathbf{P}$ & $T$ & $K_{1}$ & $\mathbf{e}_{1}$ & $K_{3}$ & $\mathbf{e}_{3}$ \\
\hline GC-001 & $35^{\circ} 53^{\prime} 22,5^{\prime \prime}$ & $7^{\circ} 17^{\prime} 22,9^{\prime \prime}$ & 1,298 & 1,074 & $-0,37$ & $089 / 27$ & 19,1 & $194 / 27$ & 23,1 \\
\hline GC-003 & $35^{\circ} 50^{\prime} 45,1^{\prime \prime}$ & $7^{0} 18^{\prime} 12,8^{\prime \prime}$ & 18,664 & 1,258 & $-0,12$ & $110 / 12$ & 23,7 & $217 / 54$ & 26,1 \\
\hline GC-004 & $35^{\circ} 51^{\prime} 17,5^{\prime \prime}$ & $7^{\circ} 14^{\prime} 34,9^{\prime \prime}$ & 3,335 & 1,073 & 0,247 & $105 / 39$ & 21,5 & $301 / 50$ & 23,8 \\
\hline GC-005 & $35^{\circ} 49^{\prime} 17,4^{\prime \prime}$ & $7^{\circ} 15^{\prime} 20,1^{\prime \prime}$ & 21,052 & 1,192 & $-0,01$ & $207 / 77$ & 4,8 & $047 / 13$ & 10,5 \\
\hline GC-006 & $35^{\circ} 48^{\prime} 36,9^{\prime \prime}$ & $7^{0} 15^{\prime} 29,7^{\prime \prime}$ & 3,744 & 1,134 & 0,318 & $178 / 39$ & 11,0 & $071 / 19$ & 17,4 \\
\hline GC-007 & $35^{\circ} 47^{\prime} 46,2^{\prime \prime}$ & $7^{0} 16^{\prime} 07,6^{\prime \prime}$ & 0,458 & 1,017 & 0,235 & $353 / 80$ & 33,7 & 090/01 & 8,6 \\
\hline GC-008 & $35^{\circ} 47^{\prime} 08,9^{\prime \prime}$ & $7^{\circ} 16^{\prime} 16,8^{\prime \prime}$ & 2,417 & 1,100 & 0,526 & $317 / 2$ & 16,2 & $226 / 27$ & 13,9 \\
\hline GC-009 & $35^{\circ} 46^{\prime} 31,5^{\prime \prime}$ & $7^{\circ} 16$ '33, & 2,009 & 1,058 & 0,405 & $156 / 10$ & 25,4 & $268 / 64$ & 16,4 \\
\hline GC-010 & $35^{\circ} 46^{\prime} 40,8^{\prime \prime}$ & $7^{\circ} 15^{\prime} 50,4^{\prime \prime}$ & 3,605 & 1,098 & 0,787 & $132 / 25$ & 33,2 & $235 / 27$ & 5,9 \\
\hline GC-011 & $35^{\circ} 46^{\prime} 01,6^{\prime \prime}$ & $7^{\circ} 15^{\prime} 21,2^{\prime \prime}$ & 3,884 & 1,090 & 0,428 & $343 / 35$ & 20,8 & $082 / 13$ & 11,9 \\
\hline GC-012 & $35^{\circ} 45^{\prime} 23,5^{\prime \prime}$ & $7^{\circ} 14^{\prime} 40,7^{\prime \prime}$ & 1,762 & 1,213 & 0,223 & $346 / 34$ & 3,8 & $090 / 20$ & 3,6 \\
\hline GC-013 & $35^{\circ} 45^{\prime} 55,4^{\prime \prime}$ & $7^{\circ} 14^{\prime} 05,2^{\prime \prime}$ & 9,553 & 1,101 & 0,365 & $166 / 01$ & 14,9 & 076/09 & 7,8 \\
\hline GC-014 & $35^{\circ} 49^{\prime} 59,7^{\prime \prime}$ & $7^{0} 11^{\prime} 58,2^{\prime \prime}$ & 1,024 & 1,075 & 0,309 & $135 / 38$ & 17,9 & $011 / 36$ & 14,9 \\
\hline GC-015 & $35^{\circ} 49^{\prime} 26,3^{\prime \prime}$ & $7^{\circ} 11^{\prime} 30,0^{\prime \prime}$ & 3,541 & 1,236 & 0,746 & 087/08 & 23,4 & $351 / 37$ & 5,9 \\
\hline GC-016 & $35^{\circ} 48^{\prime} 59,4^{\prime \prime}$ & $7^{\circ} 11^{\prime} 54,3^{\prime \prime}$ & 0,666 & 1,129 & 0,518 & $035 / 12$ & 31,0 & $165 / 71$ & 14,1 \\
\hline GC-017 & $35^{\circ} 48^{\prime} 38,9^{\prime \prime}$ & $7^{\circ} 11^{\prime} 31,2^{\prime \prime}$ & 3,971 & 1,170 & 0,613 & $117 / 19$ & 29,5 & $018 / 22$ & 9,4 \\
\hline GC-018 & $35^{\circ} 47^{\prime} 27,7^{\prime \prime}$ & $7^{0} 11^{\prime} 26,8^{\prime \prime}$ & 2,934 & 1,262 & 0,238 & $272 / 16$ & 15,2 & $005 / 11$ & 9,6 \\
\hline GC-019 & $35^{\circ} 47^{\prime} 34,2^{\prime \prime}$ & $7^{\circ} 12^{\prime} 15,6^{\prime \prime}$ & 1,985 & 1,068 & 0,530 & $257 / 36$ & 25,1 & $12 / 30$ & 9,9 \\
\hline GC-020 & $35^{\circ} 50^{\prime} 48,5^{\prime \prime}$ & $7^{\circ} 14^{\prime} 50,8^{\prime \prime}$ & 2,569 & 1,056 & 0,026 & $164 / 24$ & 28,3 & $341 / 66$ & 22,9 \\
\hline GC-021 & $35^{\circ} 51^{\prime} 09,5^{\prime \prime}$ & $7^{\circ} 14^{\prime} 01,2^{\prime \prime}$ & 0,747 & 1,138 & 0,459 & $321 / 21$ & 28,2 & $051 / 01$ & 24,0 \\
\hline GC-022 & $35^{\circ} 50^{\prime} 33,1^{\prime \prime}$ & $7^{\circ} 13^{\prime} 40,4^{\prime \prime}$ & 1,621 & 1,053 & 0,000 & $111 / 50$ & 21,7 & $343 / 27$ & 24,7 \\
\hline GC-023 & $35^{\circ} 49^{\prime} 35,1^{\prime \prime}$ & $7^{0} 13^{\prime} 43,9^{\prime \prime}$ & 6,855 & 1,244 & 0,087 & 097/58 & 5,4 & $342 / 14$ & 14,1 \\
\hline GC-024 & $35^{\circ} 50^{\prime} 16,6^{\prime \prime}$ & $7^{\circ} 13^{\prime} 10,9^{\prime \prime}$ & 0,802 & 1,053 & 0,466 & $109 / 25$ & 17,0 & $006 / 27$ & 18,8 \\
\hline GC-025 & $35^{\circ} 49^{\prime} 10,5^{\prime \prime}$ & $7^{\circ} 13^{\prime} 32,3^{\prime \prime}$ & 1,146 & 1,041 & $-0,03$ & $148 / 58$ & 25,9 & $002 / 28$ & 13,7 \\
\hline GC-026 & $35^{\circ} 48^{\prime} 09,4^{\prime \prime}$ & $7^{\circ} 14^{\prime} 39,4^{\prime \prime}$ & 0,781 & 1,212 & 0,796 & $324 / 13$ & 26,6 & $055 / 02$ & 9,6 \\
\hline GC-027 & $35^{\circ} 47^{\prime} 42,0^{\prime \prime}$ & $7^{\circ} 14^{\prime} 01,0^{\prime \prime}$ & 4,409 & 1,076 & 0,861 & $223 / 07$ & 38,2 & $356 / 80$ & 15,1 \\
\hline GC-028 & $35^{\circ} 47^{\prime} 01,4^{\prime \prime}$ & $7^{\circ} 13^{\prime} 56,7^{\prime \prime}$ & 2,386 & 1,093 & 0,389 & $167 / 58$ & 20,1 & $45 / 18$ & 12,7 \\
\hline GC-029 & $35^{\circ} 50^{\prime} 06,4^{\prime \prime}$ & $7^{0} 15^{\prime} 28,8^{\prime \prime}$ & 11,123 & 1,247 & $-0,30$ & $181 / 52$ & 3,6 & $346 / 37$ & 9,4 \\
\hline GC-030 & $35^{\circ} 49^{\prime} 25,4^{\prime \prime}$ & $7^{\circ} 16 ' 30,6^{\prime \prime}$ & 14,736 & 1,258 & $-0,38$ & $202 / 51$ & 15,1 & $062 / 32$ & 3,9 \\
\hline GC-031 & $35^{\circ} 48^{\prime} 49,1^{\prime \prime}$ & $7^{\circ} 16^{\prime} 43,5^{\prime \prime}$ & 2,901 & 1,110 & 0,174 & $196 / 48$ & 5,5 & $078 / 23$ & 5,0 \\
\hline GC-049 & $35^{\circ} 48^{\prime} 09,5^{\prime \prime}$ & $7^{0} 18^{\prime} 16,5^{\prime \prime}$ & 26,448 & 1,309 & 0,443 & $045 / 33$ & 7,5 & $271 / 47$ & 8,9 \\
\hline GC-050 & $35^{\circ} 47^{\prime} 40,1^{\prime \prime}$ & $7^{0} 17^{\prime} 59,1 "$ & 14,682 & 1,188 & 0,305 & $057 / 09$ & 9,1 & $294 / 74$ & 3,2 \\
\hline GC-057 & $35^{\circ} 52^{\prime} 07,5^{\prime \prime}$ & $7^{\circ} 16^{\prime} 23,5^{\prime \prime}$ & 3,666 & 1,078 & 0,152 & 074/07 & 20,8 & $328 / 66$ & 20,6 \\
\hline GC-058 & $35^{\circ} 53^{\prime} 07,1^{\prime \prime}$ & $7^{0} 16$ '25, & 2,560 & 1,095 & 0,127 & $091 / 42$ & 25,5 & $309 / 41$ & 23,6 \\
\hline GC-059 & $35^{\circ} 52^{\prime} 43,4^{\prime \prime}$ & $7^{\circ} 18^{\prime} 02,2^{\prime \prime}$ & 0,701 & 1,050 & $-0,18$ & $086 / 51$ & 23,1 & $296 / 35$ & 35,2 \\
\hline GC-060 & $35^{\circ} 51^{\prime} 35,3^{\prime \prime}$ & $7^{\circ} 17^{\prime} 19,0^{\prime \prime}$ & 5,440 & 1,188 & $-0,71$ & $185 / 20$ & 7,6 & $082 / 33$ & 37,8 \\
\hline GC-061 & $35^{\circ} 50^{\prime} 02,9^{\prime \prime}$ & $7^{\circ 017 ' 24,9 "}$ & 2,763 & 1,206 & 0,424 & $193 / 42$ & 3,2 & $091 / 14$ & 2,9 \\
\hline
\end{tabular}


Tabela 2. Dados de anisotropia de suscetibilidade magnética (ASM) dos sítios localizados no Granito Serra Redonda. $\boldsymbol{K}_{m}=$ suscetibilidade magnética média; $\mathbf{P}=$ grau de anisotropia; $\mathbf{T}=$ parâmetro de forma; $\boldsymbol{K}_{1}=$ lineação magnética; $\boldsymbol{K}_{3}^{m}=$ polo da foliação magnética; $\mathbf{e}_{1}$ e $\mathbf{e}_{3}=$ semiângulo do cone de dispersão ( $\left.1 \sigma\right)$ em torno da média tensorial.

\begin{tabular}{|c|c|c|c|c|c|c|c|c|c|}
\hline \multirow[b]{2}{*}{ Ponto } & \multicolumn{2}{|c|}{ Localização } & \multicolumn{3}{|c|}{ Dado escalar } & \multicolumn{4}{|c|}{ Dado direcional } \\
\hline & Long (W) & Lat(S) & $\begin{array}{c}K m \\
(m S I)\end{array}$ & $\mathbf{P}$ & $\mathbf{T}$ & $K_{1}$ & $\mathbf{e}_{1}$ & $K_{3}$ & $\mathbf{e}_{3}$ \\
\hline GC-031 & $35^{\circ} 40^{\prime} 27,5^{\prime \prime}$ & $7^{\circ} 12^{\prime} 02,9^{\prime \prime}$ & 4,124 & 1,057 & $-0,32$ & $049 / 27$ & 9,4 & $282 / 50$ & 19,3 \\
\hline GC-032 & $35^{\circ} 39^{\prime} 01,0^{\prime \prime}$ & $7^{0} 12^{\prime} 55,6^{\prime \prime}$ & 7,208 & 1,146 & $-0,13$ & $038 / 03$ & 11,4 & $305 / 43$ & 8,9 \\
\hline GC-033 & $35^{\circ} 39^{\prime} 26,8^{\prime \prime}$ & $7^{0} 13^{\prime} 14,1^{\prime \prime}$ & 13,847 & 1,166 & 0,541 & $123 / 72$ & 16,3 & $296 / 18$ & 18,7 \\
\hline GC-034 & $35^{\circ} 38^{\prime} 27,4^{\prime \prime}$ & $7^{\circ} 13^{\prime} 00,9^{\prime \prime}$ & 7,846 & 1,121 & 0,207 & $072 / 36$ & 24,6 & $260 / 53$ & 24,9 \\
\hline GC-035 & $35^{\circ} 37^{\prime} 37,5^{\prime \prime}$ & $7^{\circ} 12^{\prime} 10,0^{\prime \prime}$ & 22,633 & 1,345 & 0,254 & $264 / 03$ & 9,6 & $021 / 83$ & 7,1 \\
\hline GC-036 & $35^{\circ} 37^{\prime} 48,6^{\prime \prime}$ & $7^{\circ} 11^{\prime} 27,8^{\prime \prime}$ & 10,584 & 1,135 & $-0,01$ & $104 / 21$ & 13,8 & $207 / 31$ & 10,9 \\
\hline GC-037 & $35^{\circ} 37^{\prime} 38,3^{\prime \prime}$ & $7^{\circ} 10^{\prime} 53,9^{\prime \prime}$ & 9,961 & 1,091 & $-0,37$ & $220 / 17$ & 32,4 & $119 / 33$ & 34,2 \\
\hline GC-038 & $35^{\circ} 38^{\prime} 28,7^{\prime \prime}$ & 7011'54,2" & 5,482 & 1,135 & 0,571 & 098/57 & 16,6 & $252 / 30$ & 12,6 \\
\hline GC-039 & $35^{\circ} 39^{\prime} 03,8^{\prime \prime}$ & $7^{0} 12^{\prime} 07,8^{\prime \prime}$ & 7,000 & 1,150 & 0,673 & $057 / 29$ & 25,5 & $306 / 33$ & 13,8 \\
\hline GC-040 & $35^{\circ} 40^{\prime} 18,5^{\prime \prime}$ & $7^{\circ} 14^{\prime} 21,7^{\prime \prime}$ & 15,412 & 1,130 & $-0,39$ & $155 / 29$ & 11,0 & $252 / 13$ & 31,2 \\
\hline GC-041 & $35^{\circ} 40^{\prime} 38,9^{\prime \prime}$ & $7^{\circ} 13^{\prime} 43,1^{\prime \prime}$ & 7,910 & 1,110 & 0,755 & $021 / 58$ & 18,2 & $254 / 21$ & 16,9 \\
\hline GC-042 & $35^{\circ} 40^{\prime} 19,9^{\prime \prime}$ & $7^{\circ} 13^{\prime} 15,5^{\prime \prime}$ & 9,353 & 1,285 & 0,689 & $143 / 48$ & 10,7 & $268 / 27$ & 3,3 \\
\hline GC-043 & $35^{\circ} 40^{\prime} 54,1^{\prime \prime}$ & $7^{0} 12^{\prime} 51,8^{\prime \prime}$ & 7,649 & 1,148 & $-0,71$ & $241 / 68$ & 19,1 & $076 / 22$ & 39,0 \\
\hline GC-044 & $35^{\circ} 41^{\prime} 18,3^{\prime \prime}$ & $7^{0} 14^{\prime} 50,9^{\prime \prime}$ & 6,811 & 1,302 & 0,796 & $142 / 81$ & 22,7 & $280 / 07$ & 3,7 \\
\hline GC-045 & $35^{\circ} 41^{\prime} 38,6^{\prime \prime}$ & $7^{\circ} 14^{\prime} 27,9^{\prime \prime}$ & 5,242 & 1,116 & 0,400 & $017 / 26$ & 17,9 & $268 / 34$ & 8,4 \\
\hline GC-046 & $35^{\circ} 42^{\prime} 13,4^{\prime \prime}$ & $7^{\circ} 14^{\prime} 47,7^{\prime \prime}$ & 7,583 & 1,190 & $-0,31$ & $048 / 18$ & 10,7 & $293 / 52$ & 13,1 \\
\hline GC-047 & $35^{\circ} 43^{\prime} 43,7^{\prime \prime}$ & $7^{\circ} 17^{\prime} 34,8^{\prime \prime}$ & 4,630 & 1,066 & 0,009 & $181 / 62$ & 21,6 & $291 / 10$ & 10,4 \\
\hline GC-048 & $35^{\circ} 44^{\prime} 13,9^{\prime \prime}$ & $7^{\circ} 18^{\prime} 02,9^{\prime \prime}$ & 11,117 & 1,198 & 0,115 & $073 / 51$ & 5,7 & $313 / 22$ & 13,6 \\
\hline GC-051 & $35^{\circ} 42^{\prime} 10,5^{\prime \prime}$ & $7^{\circ} 15^{\prime} 49,4^{\prime \prime}$ & 11,288 & 1,120 & 0,318 & $152 / 45$ & 20,3 & $012 / 37$ & 18,2 \\
\hline GC-052 & $35^{\circ} 45^{\prime} 03,3^{\prime \prime}$ & $7^{0} 16 ' 30,7^{\prime \prime}$ & 0,724 & 1,031 & $-0,41$ & $285 / 50$ & 13,7 & $170 / 19$ & 21,9 \\
\hline GC-053 & $35^{\circ} 44^{\prime} 04,1 "$ & $7^{0} 16^{\prime} 36,8^{\prime \prime}$ & 1,500 & 1,107 & $-0,18$ & $113 / 26$ & 13,8 & $021 / 05$ & 22,3 \\
\hline GC-054 & $35^{\circ} 42^{\prime} 52,5^{\prime \prime}$ & $7^{\circ} 15^{\prime} 45,0^{\prime \prime}$ & 3,467 & 1,183 & $-0,37$ & $209 / 55$ & 11,9 & $305 / 04$ & 7,7 \\
\hline GC-055 & $35^{\circ} 43^{\prime} 29,8^{\prime \prime}$ & $7^{\circ} 16^{\prime} 19,8^{\prime \prime}$ & 11,844 & 1,167 & $-0,06$ & $085 / 48$ & 16,6 & $245 / 40$ & 19,7 \\
\hline GC-056 & $35^{\circ} 42^{\prime} 05,6^{\prime \prime}$ & $7^{\circ} 15^{\prime} 35,9^{\prime \prime}$ & 10,163 & 1,314 & 0,634 & $185 / 71$ & 12,5 & $283 / 03$ & 6,3 \\
\hline GC-062 & $35^{\circ} 40^{\prime} 17,2^{\prime \prime}$ & $7^{\circ} 11 ' 21,8 "$ & 5,076 & 1,132 & $-0,13$ & $042 / 17$ & 12,9 & $303 / 26$ & 9,0 \\
\hline GC-063 & $35^{\circ} 39^{\prime} 18,3^{\prime \prime}$ & 7011'09,5" & 8,205 & 1,136 & $-0,37$ & $183 / 78$ & 17,3 & $320 / 08$ & 15,3 \\
\hline GC-064 & $35^{\circ} 39^{\prime} 30,9^{\prime \prime}$ & $7^{\circ} 10^{\prime} 30,1^{\prime \prime}$ & 8,693 & 1,141 & 0,038 & $120 / 33$ & 6,7 & $248 / 44$ & 6,8 \\
\hline
\end{tabular}

tramas magnética e magmática e confirmam o potencial da ASM no mapeamento estrutural de granitoides.

A trama magnética do Granito Serra Redonda contrasta com a do Granito Campina Grande. As lineações se distribuem na direção NE-SW, com máximos de distribuição (contorno de 6\%) próximo ao centro e periferia da rede estereográfica. As foliações, por outro lado, apresentam direção NE-SW, com mergulhos preferencialmente para SE, E e subordinadamente para NE. Como no Granito Campina Grande, há uma excelente correspondência entre a foliação/bandamento ígneo medido em campo com a foliação magnética. A trama planar no Serra Redonda exibe um arranjo constituído por faixas alinhadas para NNW separando domínios de direção NE. Esse arranjo pode ser atribuído a bandas de cisalhamento extensionais, com alinhamento NNW constituindo faixas internas de cisalhamento sinistral que se conectam à zona de cisalhamento Galante situada na borda ocidental do maciço.

\section{DISCUSSÃO}

A estrutura semiconcêntrica da trama magnética do Plúton Campina Grande é similar à obtida em modelos teóricos e analógicos simulando a extrusão de domos magmá- 

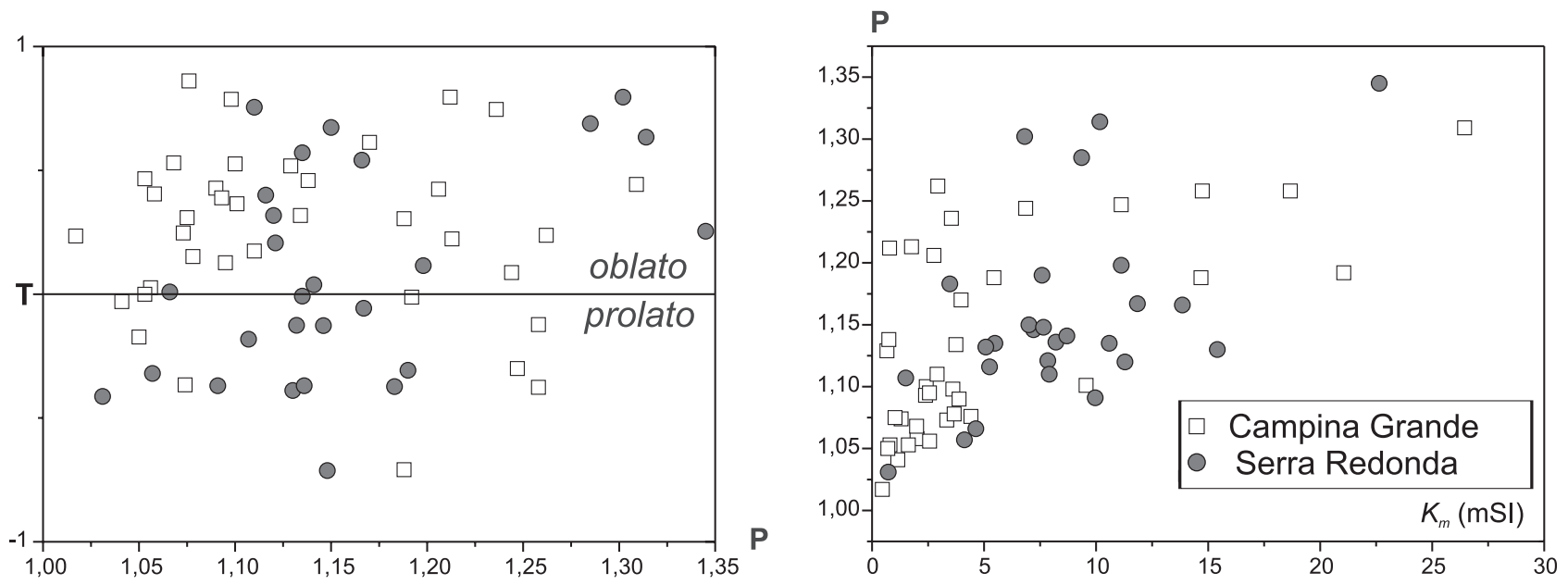

Figura 5. Gráficos $P$ (grau de anisotropia) x T (parâmetro de forma) e $P$ x $K_{m}$ (suscetibilidade magnética média).

ticos (Merle, 1998; Buisson e Merle, 2002, 2004; Závada et al., 2009). O modelamento de estruturas dômicas prediz o desenvolvimento de foliações que acompanham o contato da estrutura e que, no assoalho da intrusão, convergem para a sua zona de alimentação (vide Figura 7). No topo da intrusão, entretanto, a foliação acompanha os limites da cúpula provavelmente refletindo a deformação por achatamento periférico previsto nessa região do domo. A lineação, por outro lado, tende a seguir os contatos da estrutura e via de regra é perpendicular à direção do fluxo. De particular interesse nesses modelos, notadamente quanto à cinemática, é o mergulho sistemático da foliação convergindo para a zona de alimentação na interface do assoalho do domo com a encaixante. A orientação da foliação nesse setor define o movimento de massa na direção oposta ao mergulho do plano, e que deve ser atribuído ao efeito de arrasto entre domínios adjacentes com elevado contraste de viscosidade (massa plástica $x$ encaixante).

Embora os modelos analógicos possam ser aplicados no entendimento dos processos geológicos, eles apresentam limitações importantes de escala e reologia. Magmas graníticos, por exemplo, comumente apresentam variações composicionais e texturais que modificam suas propriedades reológicas, como a viscosidade, que depende do grau de cristalização da fração sólida do magma (Van der Molen e Paterson, 1979; Rosemberg e Berger, 2001). Além disso, as estruturas geradas nos modelos analógicos de domos magmáticos (Merle, 1998; Buisson e Merle, 2002, 2004; Závada et al., 2009) dependem exclusivamente de forças internas de corpo, o que pode não se aplicar a intrusões plutônicas formadas durante um evento orogênico. Contudo, em que pese esses fatores limitantes, notamos que há uma correspondência muito boa entre as tramas magnéticas/magmáticas do granito Campina Grande e as estruturas formadas por extrusão dômica modelada por Závada et al. (2009).

O mapeamento do plúton Campina Grande mostrou a presença de foliações praticamente paralelas na borda do granito e na encaixante regional, inclusive com desenvolvimento de milonitos acompanhando a periferia setentrional do maciço. Este tipo de feição tem sido atribuído à colocação forçada do magma com a consequente deformação das paredes encaixantes pela expansão lateral da câmara magmática (Best e Christiansen, 2001). Outro aspecto importante é a posição do maciço que, juntamente com o granito Serra Redonda, encontra-se situado no contato entre unidades litológicas de idade e composição distintas. O contato corresponderia, portanto, a uma descontinuidade crustal facilitando a migração e acumulação de magma para formar uma intrusão tabular. O padrão (semi) concêntrico da foliação mergulhando para o interior do corpo pode indicar que o atual nível de erosão expõe a seção mais basal da intrusão. $O$ arranjo da foliação é consistente com uma zona de alimentação magmática na porção sudoeste do corpo, com o magma migrando para nordeste. A lineação magnética, nesse modelo, se posicionaria na normal à direção do fluxo ígneo. Os padrões das tramas indicariam ainda que a estrutura de fluxo magmático do Granito Campina Grande seria decorrente principalmente das forças associadas à colocação deste corpo, com a deformação regional interferindo apenas localmente na trama magmática.

No plúton Serra Redonda a orientação da foliação é paralela ao alongamento do maciço, enquanto a lineação ten- 


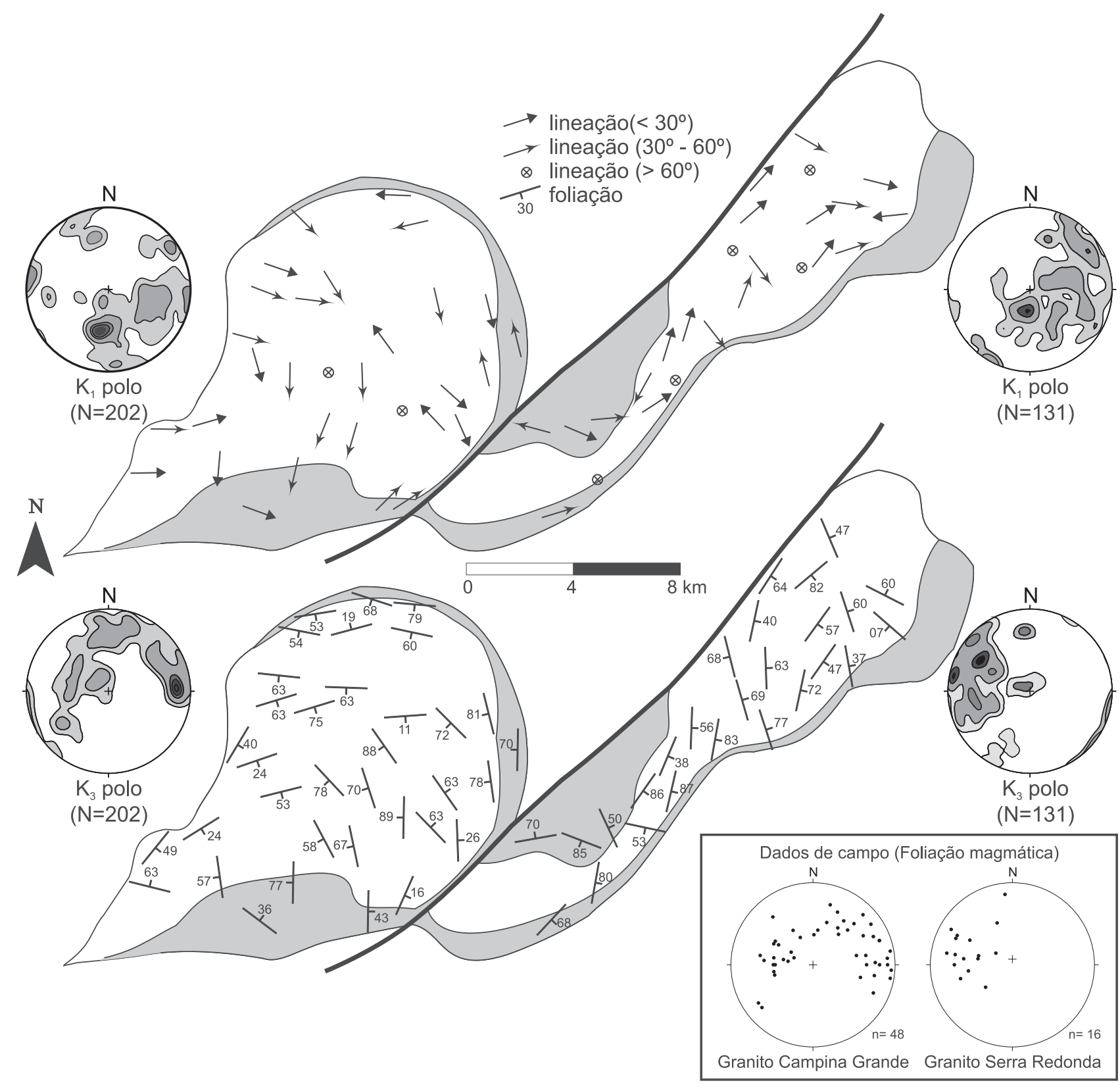

Figura 6. Foliações e lineações magnéticas do Complexo Granítico de Campina Grande. Estereogramas em semiesfera inferior com isofrequência de contagem $(2,4,6$ e 8$)$.

de a se distribuir no plano NE-SW. A foliação apresenta um padrão anastomosado que pode ter sido condicionado por bandas de cisalhamento extensionais do tipo C'-S (Figura 8). A cinemática das bandas de cisalhamento é compatível com a zona de cisalhamento sinistral de Galante, o que deve indicar uma provável contemporaneidade do conjunto de estruturas. Neste modelo, o Granito Serra Redonda é sin-tectônico à deformação transcorrente, com o seu alojamento provavelmente facilitado pela formação de estruturas extensionais locais. Outro modelo possível para interpretar as estruturas observadas no Granito Serra Redonda seria o de ascensão dos magmas em rampas com caimento para SE e E, ao longo de falhas antitéticas, com direção de fluxo de magma oposta à observada no Granito Campina Grande. O empurrão de Riachão do Bacamarte, finalmente, parece constituir uma estrutura tardia formada 
A)

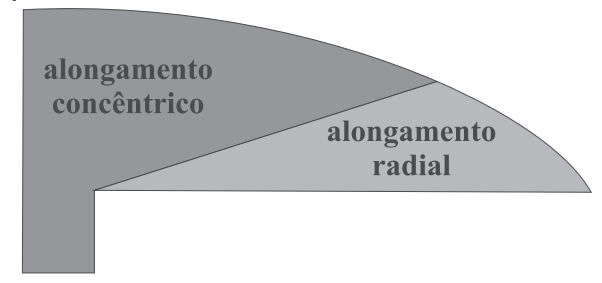

B)

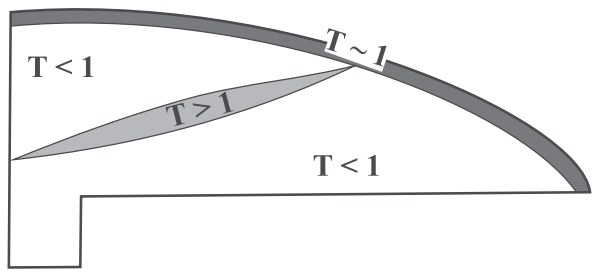

C)

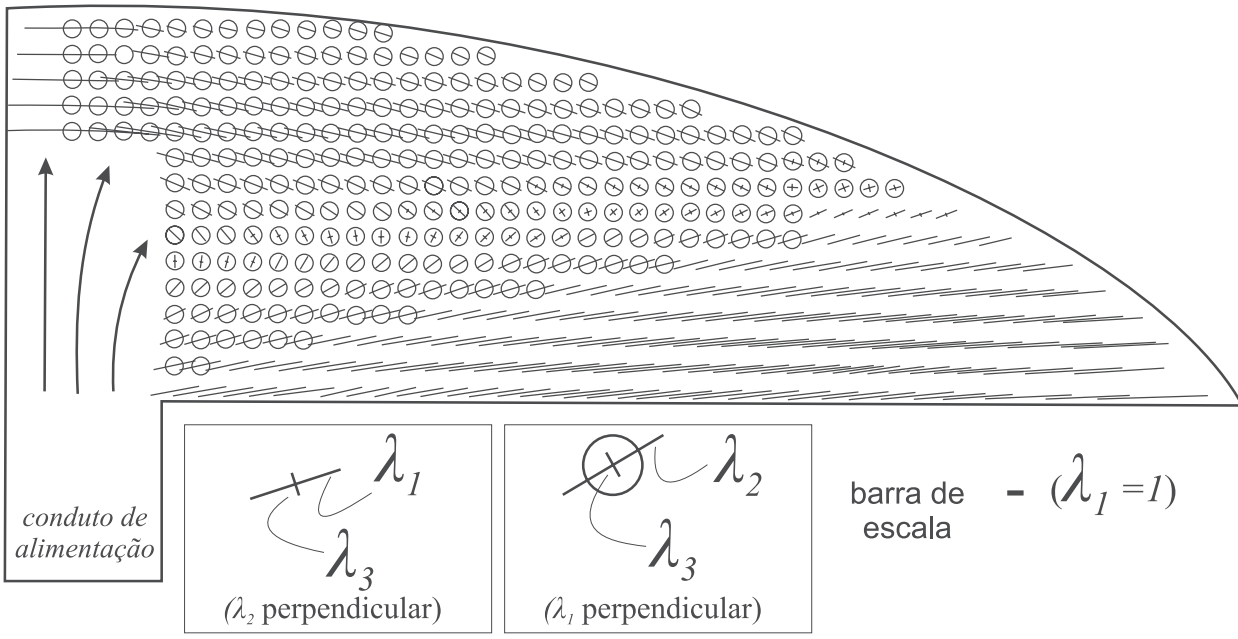

Figura 7. Padrão interno de distribuição das orientações e magnitudes dos elipsoides de forma (ou de strain) baseado em modelos teóricos de domos de lavas: A. Corte lateral ao fluxo principal em domo de lava apresentado campos de predominância de alongamento concêntrico e alongamento radial (adaptado de Buisson e Merle, 2004). B. Distribuição espacial de T (parâmetro de forma) esperada em um domo de lava (adaptado de Buisson e Merle, 2004). C. Distribuição e magnitude dos eixos dos elipsoides de forma (ou de deformação), com $\lambda_{1}$ (eixo maior de elongamento), $\lambda_{2}$ (eixo intermediário de elongamento) e $\lambda_{3}$ (eixo menor de elongamento), adaptado de Buisson e Merle, 2004.

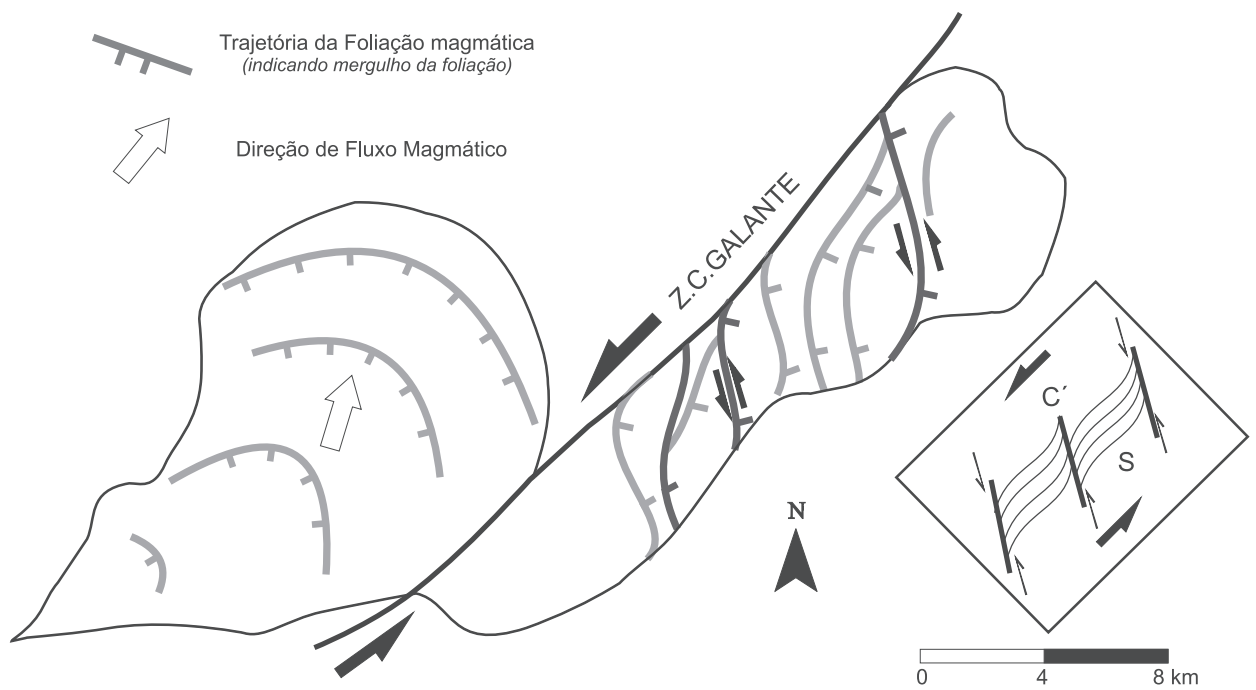

Figura 8. Trajetórias interpretadas da foliação magnética dos Granitos Campina Grande e Serra Redonda. À direita bandas de cisalhamento extensionais formadas por cisalhamento sinistral. 
nos incrementos finais da compressão regional que gerou o sistema de cisalhamento conjugado de Campina Grande (Rodrigues e Archanjo, 2008). As diferenças estruturais marcantes do GCG e GSR mostram que eles alojaram-se em ambientes tectônicos distintos, o que provavelmente se reflete na idade de cristalização um pouco mais jovem do Granito Serra Redonda com respeito ao Granito Campina Grande.

\section{CONCLUSÃO}

As formas ovalada assimétrica e tabular alongada respectivamente dos granitos Campina Grande e Serra Redonda foram desenvolvidas nos estágios finais da colagem orogênica, que reuniu rochas paleoproterozoicas e tonianas ao longo da zona de cisalhamento Galante e da Zona de Empurrão de Riachão de Bacamarte. Essa descontinuidade crustal provavelmente favoreceu a acumulação de magmas graníticos e dioríticos para formar essas intrusões. As tramas magnéticas/magmáticas dos plútons apresentam diferenças marcantes que são atribuídas a regimes de deformação distintos ativos durante a cristalização dos magmas. As tramas do Granito Campina Grande parecem refletir principalmente forças de corpo (ascensionais), com o magma migrando ao longo de uma rampa inclinada que mergulha moderadamente para sudoeste. O Granito Serra Redonda, por outro lado, está inteiramente moldado por forças tectônicas. Ele contém bandas de cisalhamento que se conectam ao cisalhamento transcorrente sinistral de Galante, e que regionalmente são compatíveis com um sistema de esforços compressivos NNW-SSE.

Os contrastes observados na trama dos plútons são em parte explicados pela diferença de idades dos granitos Campina Grande ( $\mathrm{U}-\mathrm{Pb}=581 \pm 2 \mathrm{Ma}$, TIMs, Almeida, Guimarães, Silva Filho, 2002a) e Serra Redonda (U-Pb = $576 \pm 3$ Ma, SHRIMP, Archanjo et al., 2008). Ressalta-se que estas diferenças de idades devam ser utilizadas com parcimônia, devido aos valores serem muito próximos entre si e pelas acuracidades distintas entre os métodos utilizados, o que podem indicar que as idades de ambos os granitos sejam a mesma. Os dados estruturais e geocronológicos combinados retratam ainda a natureza heterogênea e episódica da deformação orogênica, cuja sequência de eventos, no entanto, está gravada na trama magmática dos corpos plutônicos.

\section{AGRADECIMENTOS}

Os autores agradecem à FAPESP (processos: 02/136774 e 02/14687-1) pelo apoio financeiro e a técnica Msc. Daniele Brandt do Laboratório de Paleomagnetismo IAG-
-USP pelo apoio nos trabalhos laboratoriais. Ao geólogo Carlos Libório Tomba pelo apoio na amostragem de campo. E aos revisores anônimos pelas importantes contribuições sugeridas no trabalho.

\section{REFERÊNCIAS}

ALMEIDA, C. N.; GUIMARÃES, I. P.; SILVA FILHO, A. F. Petrogênese de rochas plutônicas félsicas e máficas na província Borborema, NE do Brasil: o complexo cálcio alcalino de Alto-K de Campina Grande. Revista Brasileira de Geociências, v. 32, p. 205-216, 2002a.

ALMEIDA, C. N.; GUIMARÃES, I. P.; SILVA FILHO, A. F. A-Type Post-collisional Granites in the Borborema Province- NE Brazil: the Queimadas Pluton. Godwana Research, v. 5, p. 667-681, 2002b.

ALMEIDA, F. F. M.; HASUI, Y.; BRITO NEVES, B. B.; FUCK, R. A. Brazilian structural provinces: an introduction. Earth-Sciences Reviews, v.17, p. 1-21, 1981.

ARCHANJO, C. J.; BOUCHEZ, J. L.; CORSINI, M. The Pombal Granite Pluton: magnetic fabric, emplacement and relationships with the Brasiliano strike-slip setting of NE Brazil (Paraíba State). Journal of Structural Geology, v. 16, p. 323-335, 1994.

ARCHANJO, C. J.; SILVA, E. R.; CABY, R. Magnetic fabric and pluton emplacement in a transpressive shear zone system: the Itaporanga porphyritic granitic pluton (Northeast Brazil). Tectonophysics, v. 312, p. 331-345, 1999.

ARCHANJO, C. J.; TRINDADE, R. I. F.; BOUCHEZ, J. L.; ERNESTO, M. Granite fabrics and regional-scale strain partitioning in the Seridó belt (Borborema Province, NE Brazil). Tectonics, v. 21, p. 1-13, 2002.

ARCHANJO, C. J., FETTER, A. H. Emplacement setting of the granite sheeted pluton of Esperança (Brasilian Orogen, Northeastern Brazil). Precambrian Research, v. 135, p. 193-215, 2004.

ARCHANJO, C. J.; HOLLANDA, M. H. B. M.; RODRIGUES, S. W. O; BRITO NEVES, B. B.; ARMSTONG, R. Fabrics of pre- and syntectonic granite plutons and chronology of shear zones in the Eastern Borborema Province, NE Brazil. Journal of Structural Geology, v. 30, p. 310-336, 2008.

BEST, M. G.; CHRISTIANSEN, E. H. Igneous Petrology. Oxford: Blackwell Science. 2001. 458 p. 
BOUCHEZ, J. L. Granite is never isotropic: an introduction to AMS studies of granitic rocks. In: BOUCHEZ, J. L.; HUTTON, D.; STEPHENS, W. E. Granite: from segregation of melt to emplacement fabric. Boston: Kluwer, 1997. p. 95-112.

BOUCHEZ, J. L. Magnetic susceptibility anisotropy and fabrics in granites. Earth and Planetary Science Letters, v. 330, p. 1-14, 2002.

BRITO NEVES, B. B.; CAMPOS NETO, M. C. C.; VAN SCHMUS, W. R.; SANTOS, E. J. O Sistema PajeúParaíba e o Maciço São José do Campestre no Leste da Borborema. Revista Brasileira de Geociências, v. 31, p. 173-184, 2001a.

BRITO NEVES, B. B.; CAMPOS NETO, M. C. C.; VAN SCHMUS, W. R, FERNANDES, M. G. G.; SOUZA, L. O. O Terreno Alto Moxotó no Leste da Paraíba (Maciço Caldas Brandão). Revista Brasileira de Geociências, v. 31, p. 185-194, 2001b.

BRITO NEVES, B. B.; PASSARELLI, C. R., BASEI, M. A. S., SANTOS, E. J. Idades U-Pb em Zircão de Alguns Granitos Clássicos da Província Borborema. Geologia USP: Série Cientifica, São Paulo, v. 3, p. 25-138, 2003.

BRITO NEVES, B. B.; SANTOS, E. J.; VAN SCHMUS, W. R. Tectonic history of the Borborema Province. In: CORDANI, U. G.; Milani, E. J.; THOMAZ FILHO, A.; CAMPO, D. A. Tectonic evolution of the South America. Rio de Janeiro: 31st International Geological Congress, 2000. p. 151-182.

BROWN, M.; SOLAR, G. S. Granite ascent and emplacement during contracional deformation in convergent orogens. Journal of Structural Geology, v. 20. p. 1365-1393, 1998.

BUISSON, C.; MERLE, O. Experiments on internal strain in lava dome cross sections. Bulletin of Vulcanology, v. 64, p. 363-371, 2002.

BUISSON, C.; MERLE, O. Numerical simulation of strain within lava domes. Journal of Structural Geology, v. 26, p. 847-853, 2004.

CRUDEN, A. R. Emplacement and growth of plutons: implications for rates of melting and mass transfer in continental crust. In: BROWN, M.; RUSHMER, T. Evolution and Differentiation of the Continental Crust. Cambridge: Cambridge University Press, 2006. p. 455-519.
FERREIRA, V. P.; SIAL, A. N.; PIMENTEL, M. M; MOURA, C. A. V. Acidic to intermediate magmatism and crustal evolution in the Transversal Zone, northeastern Brazil. In: MANTESSO NETO, V.; BARTORELLI, A.; CARNEIRO, C. D.; BRITO NEVES, B. B. (Org.) Geologia do continente Sul-Americano. São Paulo: BECA, 2004. p. 189-201.

HUTTON, D. H. W. Granite emplacement mechanism and tectonic controls: interferences from deformation studies. Transactions of the Royal Society of Edinburg: Earth Sciences, v. 83, p. 377-382, 1988.

KOZUCH, M. Isotopic and trace element geochemistry of early Neoproterozoic gneissic and metavolcanic rocks in the Cariris Velhos Orogen of Borborema Province, Brazil, and their bearing on tectonic setting. 2003. $199 \mathrm{f}$. Tese (Doutorado), University of Kansas, 2003.

MERLE, O. Internal strain within lava flows from analogue modeling. Journal of Volcanology and Geothermal Research, v.81, p. 189-206, 1998.

NEVES, S. P.; BRUGUIER, O.; VAUCHEZ, A.; BOSCH, D.; SILVA, J. M. R.; MARIANO, G. Timing of crust formation, deposition of supracrustal sequences, and Transamazonian and Brasiliano metamorphism in eastern Borborema Province (NE Brazil): implications for western Gondwana assembly. Precambrian Research, v. 149, p. 197-216, 2006.

RODRIGUES, S. W. O. Evolução estrutural e geocronológica da Província Borborema na região de Campina Grande (PB). 2008. 178 f. Tese (Doutorado) - Instituto de Geociências, Universidade de São Paulo, São Paulo, 2008.

RODRIGUES, S. W. O.; ARCHANJO, C. J. Microestruturas e tramas de eixo $\mathrm{C}$ de quartzo em milonitos do Sistema de Cisalhamento Campina Grande (PB), Província Borborema. Revista Brasileira de Geociências, v. 38, p. 392-405, 2008.

RODRIGUES, S. W. O.; ARCHANJO, C. J.; LAUNEAU, $P$. Determinação da orientação preferencial de forma (OPF) de silicatos em rochas graníticas: Granito Campina Grande (PB). Revista Brasileira de Geociências, v. 39, p. 435-451, 2009.

RODRIGUES, S. W. O.; BRITO NEVES, B. B. Padrões isotópicos SM-Nd no limite entre os Terrenos Alto Pajeú e Alto Moxotó (PB). Revista Brasileira de Geociências, v. 38, p. $209-225,2008$. 
ROSENBERG, C. L.; BERGER, A. Syntectonic melt pathways in granite, and melt-induced transition in deformation mechanisms. Physics and Chemistry of the Earth, Part A, v. 26, p. 287-293, 2001.

SÁ, J. E. F.; TRINDADE, R. I. F.; HOLLANDA, M. H. B. M.; ARAÚJO, J. M. M.; GALINDO, A. C.; AMARO, V. E.; SOUZA, Z. S.; VIGNERESSE, J. L., LARDEAUX, J. M.. Brasiliano syntectonic alkaline granites emplaced in a strike-slip/extensional setting. Anais da Academia Brasileira de Ciências, v. 71, p. 17-27, 1999.

SAMPAIO, M. A; GUIMARÃES, I. P.; ALMEIDA, C. N.; CARMONA, L. C. M. Rb-Sr and Sm-Nd isotope geochemistry of granitoids from the Esperança granitic complex, Paraíba state, Borborema Province, Northeast Brazil. In: SOUTH AMERICAN SYMPOSIUM OF ISOTOPE GEOLOGY, 4., 2003, Salvador. Short Papers... Salvador: CBPM/IRD, 2003, p. 122-123.

SANTOS, E. J. Complexo Granítico Lagoa das Pedras: acresção e colisão na região de Floresta (Pernambuco), Província Borborema. 1995. 220 f. Tese (Doutorado), Instituto de Geociências, Universidade de São Paulo, São Paulo, 1995.

SANTOS E. J.; FERREIRA, C. A.; SILVA JÚNIOR, J. M. F. Geologia e recursos minerais do Estado da Paraiba: texto explicativo do mapa geológico e de recursos minerais. Recife: CPRM, 2002. 2 mapas, Escala 1:500.000. 1 CD-ROM.

SANTOS, E. J.; MEDEIROS, V. C. Constraints from granitic plutonism on proterozoic crustal growth of trasverse zone, Borborema Province, NE Brazil. Revista Brasileira de Geociências, v. 29, p. 73-84, 1999.

SANTOS, E. J.; NUTMAN, A. P.; BRITO NEVES, B. B. Idades SHRIMP U-Pb do Complexo Sertânia: implicações sobre a evolução tectônica da Zona Transversal, Província Borborema. Geologia USP: Série Cientifica, São Paulo, v. 4, p. 1-12, 2004.

SANTOS, E. J.; SOUZA NETO, J. A.; CARMONA, C. M.; ARMSTRONG, R.; SIAL, A. N.; CHEMALE Jr, F.; BRITO, R. S. C. Paleoproterozoic Juvenile Accretion in the Alto Moxoto Terrane, Borborema Province, Northeast Brazil. In: SOUTH AMERICAN SYMPOSIUM OF ISOTOPE GEOLOGY. 6., 2008, San Carlos de Bariloche. Book of Abstracts... Buenos Aires, Argentina: INGEIS Instituto de Geocronología y Geología Isotópica, 2008. p. 166. 1 CD-ROM.
SANTOS, E. J.; VAN SCHMUS, W. R.; KOZUCH, M.; BRITO NEVES, B. B. The Cariris Velhos Tectonic Event in Northeast Brazil. Journal of South American Earth Sciences, v. 29, p. 61-76, 2010.

VAN DER MOLEN, I.; PATERSON, M. S. Experimental deformation of partially melted granite. Contribution Mineralogical Petrology, v. 70, p. 299-318, 1979.

VAUCHEZ, A.; NEVES, S. P. Transcurrent shear zones and magma emplacement in Neoproterozoic belts of Brazil. In: BOUCHEZ, J. L.; HUTTON, D.; STEPHENS, W. E. Granite: from segregation of melt to emplacement fabric. Boston: Kluwer, 1997, p. 275-293.

VIGNERESSE, J. L. Control of granite emplacement by regional deformation. Tectonophysics, v. 249, p. 173-186, 1995.

ZÁVADA, P.; KRATINOVÁ, Z.; KUSBACH, V.; SCHULMANN, K. Internal fabric development in complex lava domes. Tectonophysics, v. 466, p. 101-103, 2009.

WEINBERG, R. F.; SIAL, A. N.; MARIANO, G. Close spatial relationship between plutons and shear zones. Geology, v. 32, p. 377-380, 2004. 
